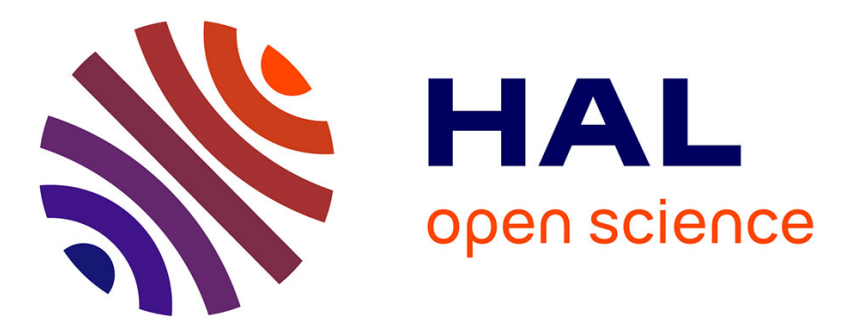

\title{
Experimental study of the impact of punching operations on the high cycle fatigue strength of $\mathrm{Fe}-\mathrm{Si}$ thin sheets
}

Helmi Dehmani, Charles Brugger, Thierry Palin-Luc, Charles Mareau, Samuel Koechlin

\section{To cite this version:}

Helmi Dehmani, Charles Brugger, Thierry Palin-Luc, Charles Mareau, Samuel Koechlin. Experimental study of the impact of punching operations on the high cycle fatigue strength of Fe-Si thin sheets. International Journal of Fatigue, 2016, 82, Part 3, pp.721-729. 10.1016/j.ijfatigue.2015.09.030 . hal02486114

\section{HAL Id: hal-02486114 \\ https://hal.science/hal-02486114}

Submitted on 20 Feb 2020

HAL is a multi-disciplinary open access archive for the deposit and dissemination of scientific research documents, whether they are published or not. The documents may come from teaching and research institutions in France or abroad, or from public or private research centers.
L'archive ouverte pluridisciplinaire HAL, est destinée au dépôt et à la diffusion de documents scientifiques de niveau recherche, publiés ou non, émanant des établissements d'enseignement et de recherche français ou étrangers, des laboratoires publics ou privés. 


\title{
Experimental study of the impact of punching operations on the high cycle fatigue strength of Fe-Si thin sheets
}

\author{
H. Dehmani ${ }^{\mathrm{a}, \mathrm{b}, c, *}$, C. Brugger ${ }^{\mathrm{a}}$, T. Palin-Luc ${ }^{\mathrm{a}}$, C. Mareau ${ }^{\mathrm{b}}$, S. Koechlin ${ }^{\mathrm{c}}$ \\ ${ }^{a}$ Arts et Metiers ParisTech, I2M, CNRS, Esplanade des Arts et Métiers, Talence, France \\ ${ }^{\mathrm{b}}$ Arts et Metiers ParisTech, LAMPA, Boulevard du Ronceray, Angers, France \\ ${ }^{\mathrm{c}}$ Emerson-Leroy Somer, Boulevard Marcellin Leroy, Angoulême, France
}

Keywords:

Fe-Si steel sheet

High cycle fatigue

Crack initiation

Defect

Punching

\begin{abstract}
A B S T R A C T
In this paper, the impact of punching operations on the high cycle fatigue strength of Fe-Si thin sheets is investigated. High cycle fatigue tests are performed on both punched and polished edge specimens. Results show a significant decrease of the fatigue strength in the case of punched specimens. Different factors are found to be responsible for this degradation. First, according to SEM observations of fracture surfaces and to 3D surface topography, fatigue crack initiation is strongly governed by the geometrical defects resulting from punching operations. Second, important tensile residual stresses, which are analyzed using X-ray diffraction techniques, are observed on punched edges. Depending on the loading conditions, it is possible for the residual stress field to be redistributed as a result of cyclic plasticity. Third, punching operations are responsible for the introduction of a plastically hardened zone which, according to both micro-hardness measurements and diffraction data, is about $200 \mu \mathrm{m}$ deep. Based upon this experimental dataset, the parameters of the Murakami criterion are identified. This criterion is found to provide a reasonable description of the experimental results when the residual stresses around punched edges are accounted for.
\end{abstract}

\section{Introduction}

Because of their improved magnetic properties, a new generation of electrical steel sheets is being increasingly used for building high-speed electric motors, hybrid and electric traction machines. The reduction of iron losses in these Fe-Si thin sheets is achieved by decreasing the thickness (below $0.5 \mathrm{~mm}$ ), increasing the grain size, and adjusting the chemical composition (mainly the silicon content). The fatigue properties of $\mathrm{Fe}-\mathrm{Si}$ thin sheets are influenced not only by these geometrical and metallurgical features, but also by the alterations caused by fabrication processes. However, though a significant influence of fabrication processes on fatigue properties is generally observed [1,2], very few studies focus on $\mathrm{Fe}-\mathrm{Si}$ thin sheets, for which the grain size is comparable to the thickness. In the present work, the impact of punching operations, involved in the mass production of electrical machines, on the fatigue properties of $\mathrm{Fe}-\mathrm{Si}$ thin sheets is therefore investigated.

\footnotetext{
* Corresponding author at: Arts et Metiers ParisTech, I2M, CNRS, Esplanade des Arts et Métiers, Talence, France.

E-mail addresses: helmi.dehmani@ensam.eu (H. Dehmani), charles.brugger@ ensam.eu (C. Brugger), thierry.palin-luc@ensam.eu (T. Palin-Luc), charles.mareau@ ensam.eu (C. Mareau).
}

Many studies have dealt with the effect of cutting processes on the fatigue behavior of different steel grades for different thicknesses. Punching is often considered as the most damaging process among cutting techniques because it generates important geometrical, metallurgical and mechanical alterations of the edges. Indeed, various geometrical defects, including surface irregularities, exist on cut edges. Such defects, because they cause stress concentration, are favorable to fatigue crack initiation [1]. For instance, for three different steel grades, the fatigue strength at $5 \times 10^{6}$ cycles of $15 \mathrm{~mm}$ thick punched plates is half that of drilled ones [2]. According to these authors, the degradation of the fatigue resistance of punched plates results from both the existence of a $2 \mathrm{~mm}$ deep damaged zone and the important surface roughness. Also, high plastic strain localization around edges is usually observed during punching operations. Large plastic strains, because they result in an increase of the concentration of crystalline defects (e.g. dislocations), are generally responsible for a deterioration of both magnetic [3-5] and mechanical properties $[6,7]$ including fatigue strength. Finally, important residual stresses, which significantly affect fatigue resistance, may exist because of punching [8-10].

In this paper, the impact of punching operations on the high cycle fatigue strength of $\mathrm{Fe}-\mathrm{Si}$ thin sheets is investigated. More 
specifically, the present work aims at studying the impact of punching operations on fatigue crack initiation for different stress ratios. For this purpose, high cycle fatigue tests are performed on specimens with either punched or polished edges. In order to understand the crack initiation causes, SEM observations of fracture surfaces are carried out and the geometries of cut edges are investigated using 3D topography. These experimental data allow for determining the geometrical features of the crack initiation sites. To determine the depth up to which the material is affected by punching, micro-hardness measurements are performed at different distances from the edges. X-ray diffraction techniques are used to estimate the residual stresses resulting from punching operations. Finally, based on the experimental results, the relevance of the Murakami criterion is evaluated.

\section{Material description and specimens preparation}

\subsection{Material}

In the present work, the fatigue behavior of a non-oriented fully-processed sheet of $\mathrm{Fe}-\mathrm{Si}$ electrical steel is investigated. It is delivered in the form of rolled sheets with a $350 \mu \mathrm{m}$ nominal thickness. Its chemical composition is given in Table 1. Metallographic observations (Fig. 1) reveal an equiaxed microstructure. The average grain size, which has been estimated in agreement with NF EN ISO 2624 standard, is about $100 \mu \mathrm{m}$. According to the pole figures, which were determined using EBSD techniques (Fig. 2), the Fe-Si sheet exhibits a slight rolling texture. Mechanical properties, which have been determined for monotonic quasi-static uniaxial tension conditions along the rolling direction at room temperature, are given in Table 2 .

\subsection{Specimens}

Smooth specimens have been used for the fatigue tests. They were punched out from sheets with the same punching conditions than those used for producing real components. Fatigue specimens are orientated so that their longitudinal axis is parallel to the rolling direction (Fig. 3).

Punched edges display a typical morphology with four different zones (Fig. 4): the roll over, the sheared zone, the fracture zone and the burr. The first zone, called the roll-over, is located on the top of the sheet. It results from the pressure exerted by the punch at the beginning of the cutting operation. The second zone, called the sheared zone, is a consequence of the shearing associated with the punch penetration. A smooth surface is generally observed in the sheared zone. The third zone, called the fracture zone, is caused by the continuous downward movement of the punch. In comparison with the sheared zone, the edge surface is found to be much more uneven in the fracture zone. Finally, a burr is observed at the bottom of punched edges because of the metal elongation resulting from the separation into two pieces. This morphology has been observed by various authors on steel sheets with different thicknesses ranging from 0.5 to $15 \mathrm{~mm}[2,6]$.

To evaluate the impact of punching on fatigue properties, some fatigue tests were also performed on specimens with polished edges. Polishing is expected to remove geometrical defects, to reduce the plastically strained region and to attenuate the residual stresses resulting from punching. Polishing operations were done using silicon carbide papers from P1200 to P4000 grades. The zone which is removed as a result of polishing is about $200 \mu \mathrm{m}$ deep, as described in Fig. 4. Though metallographic observations confirm the removal of geometrical defects, local hardening and residual stresses are not fully removed (see Sections 3.5 and 3.6).
Table 1

Chemical composition of the studied Fe-Si alloy.

\begin{tabular}{lllll}
\hline Chemical element & $\mathrm{Si}$ & $\mathrm{Mn}$ & $\mathrm{Al}$ & $\mathrm{Fe}$ \\
\hline Mass (\%) & $2-3.5$ & $0.2-0.6$ & $0.4-1.2$ & $95-98$ \\
\hline
\end{tabular}

\subsection{Fatigue test conditions}

High cycle fatigue tests were performed in air, under uniaxial tension loading, and load control, at a loading frequency of $65 \mathrm{~Hz}$, using a resonant fatigue testing machine (Vibrophore type). To assess the effect of the stress ratio on the fatigue behavior, the punched specimens were tested at room temperature $\left(\simeq 20^{\circ} \mathrm{C}\right)$ for three loading ratios: $0.1,0.3$ and 0.5 . The polished specimens were also tested at room temperature with a constant loading ratio of 0.1 . Fatigue tests were stopped either because of a frequency drop of $1 \mathrm{~Hz}$, corresponding in most cases to the total specimen failure (broken into 2 parts), or when a number of $5 \times 10^{6}$ cycles was reached.

\subsection{Three dimensional surface topography}

To evaluate the geometrical alterations resulting from punching operations, three dimensional surface topography analyses of punched edges were performed using a Bruker Contour GT optical profilometer. The scanned zone is $30 \mathrm{~mm}$ long. It contains the entire reduced section and part of the specimen radius (see Fig. 3 for specimen geometry and axes definition). The resolution used for surface sampling is $0.89 \mu \mathrm{m}$ along the $Y$ and $Z$ directions and $10 \mathrm{~nm}$ along the $X$ direction. To reduce noise, a statistical filter is applied to the data after sampling.

\subsection{Micro-hardness}

Micro-hardness measurements were performed on the face of a Fe-Si sheet according to the NF ISO 6507-1 standard, using a fully automatic hardness tester (Struers DURAMIN A300D) and a $500 \mathrm{~g}$ mass. Indentations are spaced with a $500 \mu \mathrm{m}$ distance to avoid measurement interferences.

\subsection{Residual stress analyses}

To estimate residual stresses, different experimental techniques exist [11]. In the present work, X-ray diffraction techniques are used to determine residual stress $\left(\sigma_{y y}\right)$ along the loading direction on punched and polished edges (Fig. 13). Because of the low sheet thickness and the large grain size, the diffracting volume is not large enough to apply the classical $\sin ^{2} \Psi$ method [12] when a single edge is irradiated. To circumvent this difficulty, X-ray diffraction analyses were performed on a stack of 10 specimens with the same orientation (with the burr side on the Z-direction, see Fig. 5).

Residual stress analyses were carried out using a PROTO iXRD diffractometer equipped with a chromium anode. Peak positions were measured with two scintillation detectors with a $2 \theta$ range of $18.5^{\circ}$ each. Residual stresses were evaluated on an area delimited with a circular collimator (diameter $2 \mathrm{~mm}$ ). To estimate the in-depth distribution of longitudinal residual stresses, successive material removal operations were performed up to a depth of $300 \mu \mathrm{m}$. An electrochemical polishing technique with a solution of salted water was used for material removal operations. 


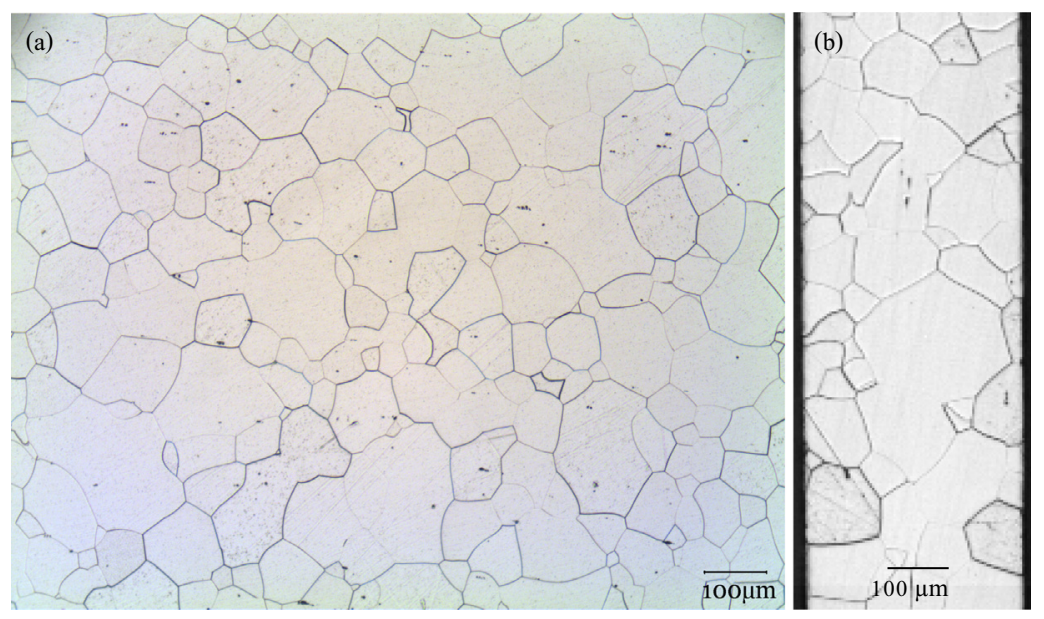

Fig. 1. Microstructure of the studied Fe-Si rolled sheets after Nital etching $4 \%$. (a) Face and (b) cross section.
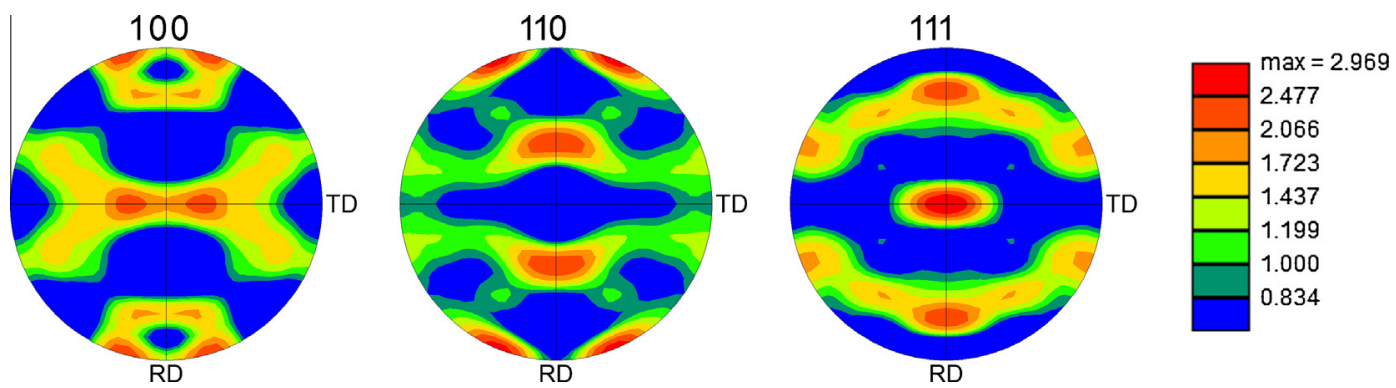

Fig. 2. Pole figures of the studied Fe-Si rolled sheet.

Table 2

Mechanical properties of the studied Fe-Si sheet along the rolling direction under monotonic quasi-static tension.

\begin{tabular}{llll}
\hline$E(\mathrm{GPa})$ & $\sigma_{y}(\mathrm{MPa})$ & $R_{m}(\mathrm{MPa})$ & $A(\%)$ \\
\hline 180 & $\simeq 400$ & $\simeq 500$ & 18 \\
\hline
\end{tabular}

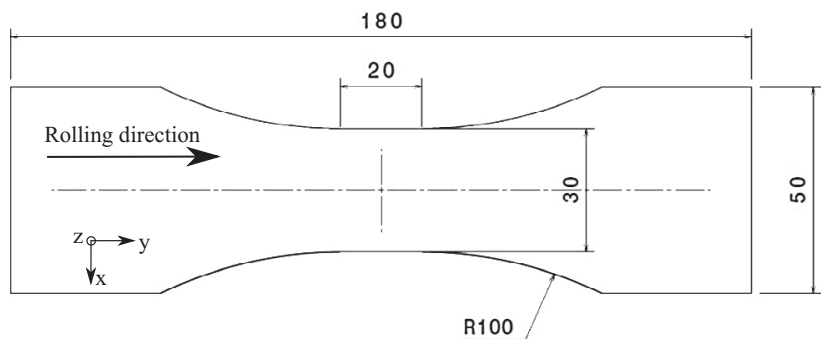

Fig. 3. Specimen geometry used for the fatigue tests (thickness: $350 \mu \mathrm{m}$ ).

\section{Results and discussion}

\section{1. $S-N$ curves}

The S-N curves corresponding to punched and polished edge specimens are presented in Fig. 6. For confidentiality reasons, all the S-N curves are plotted with maximum stress values normalized by the fatigue strength determined for punched specimens for a loading ratio $R=0.1$. To follow crack initiation and crack propagation, some punched specimens were observed with a high resolution CCD camera. For a given specimen, the evolution of the crack length as a function of the number of cycles can be plotted (see Fig. 7). The smallest crack detectable with such in-situ monitoring technique is $0.174 \mathrm{~mm}$. According to these results, the propagation stage is short and represents less than $1 \%$ of the total number of cycles to failure. Consequently, one can consider that the $\mathrm{S}-\mathrm{N}$ curves are given for initiation of a small crack, propagation being negligible. Since the depth which is affected by punching and polishing operations (less than $0.2 \mathrm{~mm}$, see Section 3.5) is the same order of magnitude as the spatial resolution of the monitoring technique, any difference between polished and punched would be hardly detectable. Therefore, though no observations were made, the propagation stage is also expected to be short in comparison with the initiation stage for polished specimens.

In comparison with polished specimens, the fatigue median strength obtained at $5 \times 10^{6}$ cycles using the staircase method shows a drop of about $30 \%$ for punched specimens. For high stress levels, the difference between punched and polished specimens reduces as fatigue crack initiation is more and more governed by macroscopic plasticity.

\subsection{Effect of the mean normal stress}

The effect of the mean normal stress is summarized in the Haigh diagram plotted in Fig. 8 for which the dashed line represents the $\sigma_{\max }=R_{m}$ threshold. In order to evaluate whether the influence of the mean stress is correctly described by the Haigh diagram or not, some tests were carried out on punched specimens for two additional loading ratios $R=0.3$ and $R=0.5$. Using the fatigue strength values corresponding to three different loading ratios, a threshold at $5 \times 10^{6}$ cycles has been identified. Based on these experimental results, the Haigh diagram correctly describes the effect of the mean normal stress. 


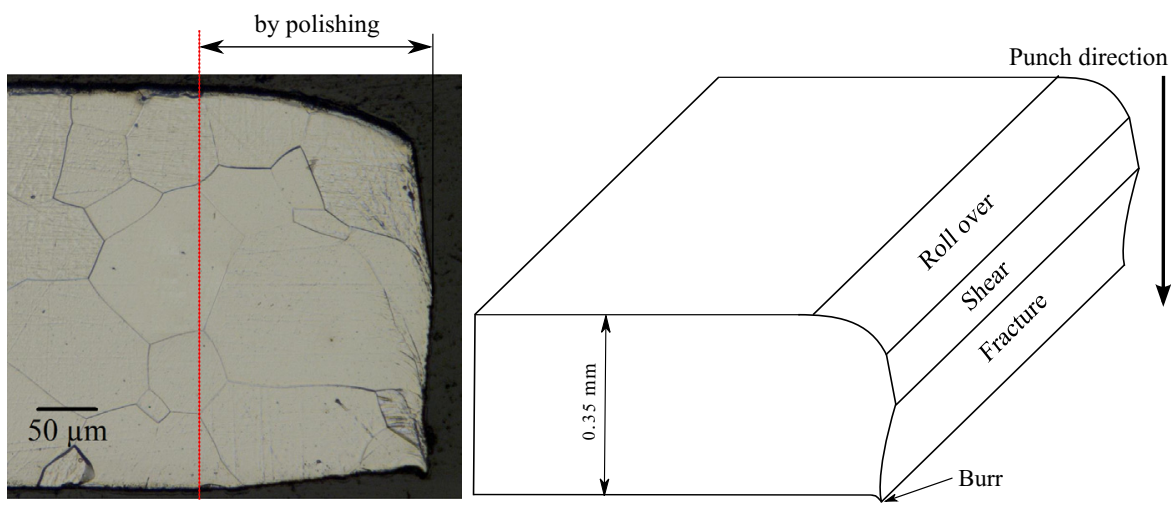

Fig. 4. Different zones observed on the punched edges.

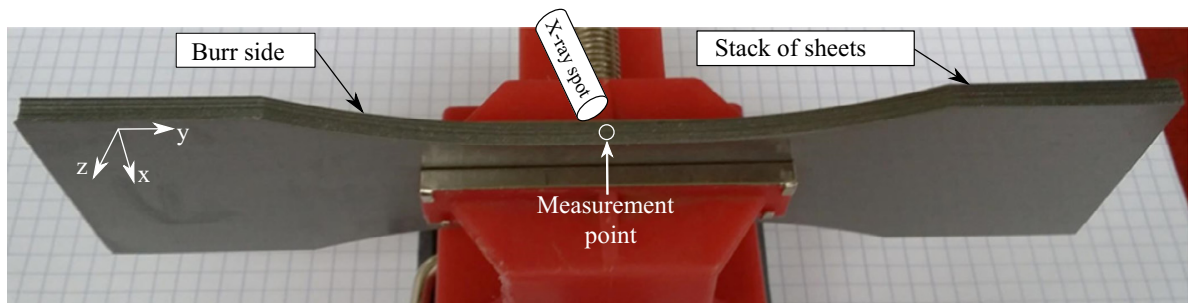

Fig. 5. Experimental set-up used for performing residual stress analyses on a stack of 10 specimens.

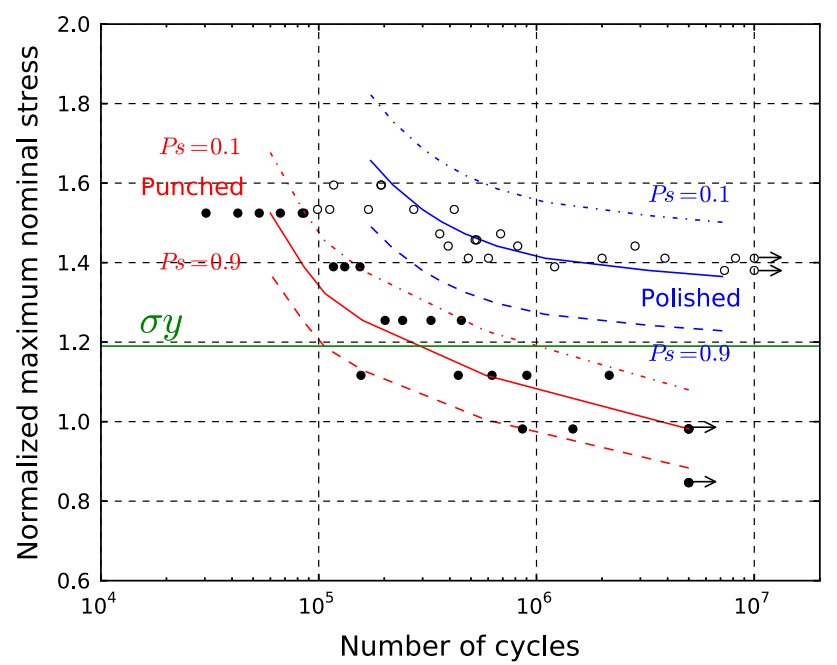

Fig. 6. S-N curves obtained for punched and polished edge specimens for a stress ratio $R=0.1$.

\subsection{Fractographic observations}

In order to identify the crack initiation mechanisms, the fracture surfaces of punched and polished edge specimens have been observed using Scanning Electron Microscopy (SEM). For punched specimens, SEM observations reveal that, in most cases, geometrical defects on the edges are responsible for crack initiation (see Fig. 9b). Cracks initiate either in the fracture zone or just between the sheared and fracture zones of the edge. In both cases, punching defects are found in the fracture zone. Sometimes, a grain is clearly visible on the edge of the fracture surface (in the crack initiation zone), as illustrated in Fig. 9c. At this stage, it is not clear whether grain debonding occurred during punching operations, thus generating a pre-crack, or cyclic loading resulted in inter-granular crack initiation.
On fracture surfaces, different areas are observed: an initiation zone where the river lines converge to a punching defect located on the edge (Fig. 10b), a crystallographic zone, which corresponds to the stable propagation of fatigue cracks (Fig. 10c) and a ductile zone relative to the final fracture (Fig. 10d). The transition between the initiation zone and the crystallographic zone is often clearly visible. It is usually observed at a distance from the edge between 0.5 and $1.5 \mathrm{~mm}$.

For polished edge specimens, the identification of the initiation zone is more difficult. In some cases, two possible initiation sites can be found. For instance, in Fig. 9a, fatigue cracks initiate either on a rolling defect on the upper face (point A) or because of a debonded grain on the edge (point B). In contrast with polished specimens, no crack initiation from faces was observed for

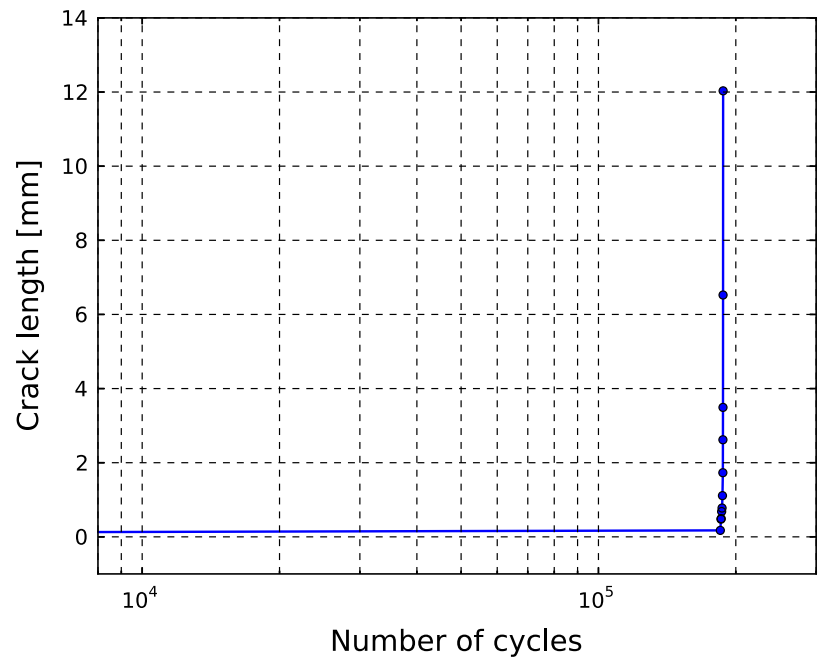

Fig. 7. Crack length measurements during a fatigue test ( $R=0.1$ ). 


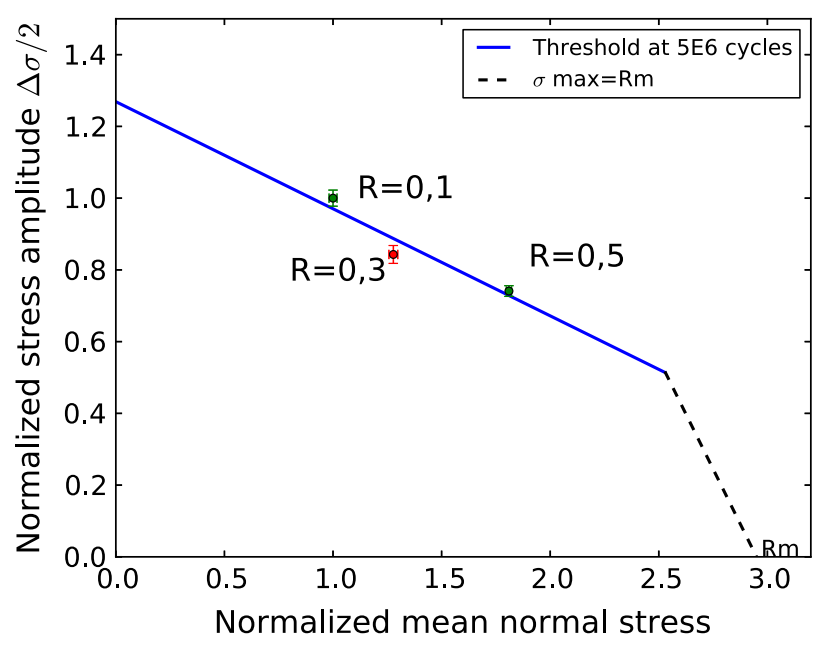

Fig. 8. Adimensional Haigh diagram obtained for punched specimens.

punched specimens. Such results demonstrate that there is a competition between rolling-induced defects and microstructural defects (weakest grain boundary for instance) for polished specimens. In the case of punched specimens, punching-induced defects on the edge are large enough to drive fatigue crack initiation.

\subsection{Three dimensional surface topography}

Specimen edges were scanned using 3D surface topography before fatigue testing. Post-failure observations allow for identifying the critical defect being responsible for fatigue crack initiation (Fig. 11).

For punched specimens, observations show irregular surfaces with many defects in the different zones, as illustrated in Fig. 11. Four types of defects were identified: (i) downward vertical scratches, (ii) local thickness reductions, (iii) hollows in the sheared zone, and (iv) hollows in the fracture zone. Topography results confirm the fractographic observations of punched specimens for which type (iv) defects, which are located in the fracture zone on the edge, are often critical with regard to fatigue crack initiation.

When a polishing operation is applied, geometrical defects are removed from specimen edges. The fatigue strength drop observed for punched specimens is therefore partially explained by the high concentration of punching defects. On polished edge specimens, most of the fatigue cracks initiate on an edge despite the absence of geometrical defects. It is clear then that plastic strain and residual stresses resulting from punching operations also play a role in fatigue crack initiation.

\subsection{Micro-hardness}

Micro-hardness is observed to be quite uniform on the sheet with a mean value of $207 \mathrm{HV}$ and a standard deviation of $7 \mathrm{HV}$ (Fig. 12a and c), it is found to depend slightly on the local microstructural features: lowest values are relative to indentations in the middle of a grain, while highest values are obtained for indentations close to grain boundaries (Fig. 12b). Measurement uncertainties are about $\pm 9 \mathrm{HV}$. The statistical distribution of micro-hardness is illustrated in Fig. 12c. Additional micro-hardness measurements performed

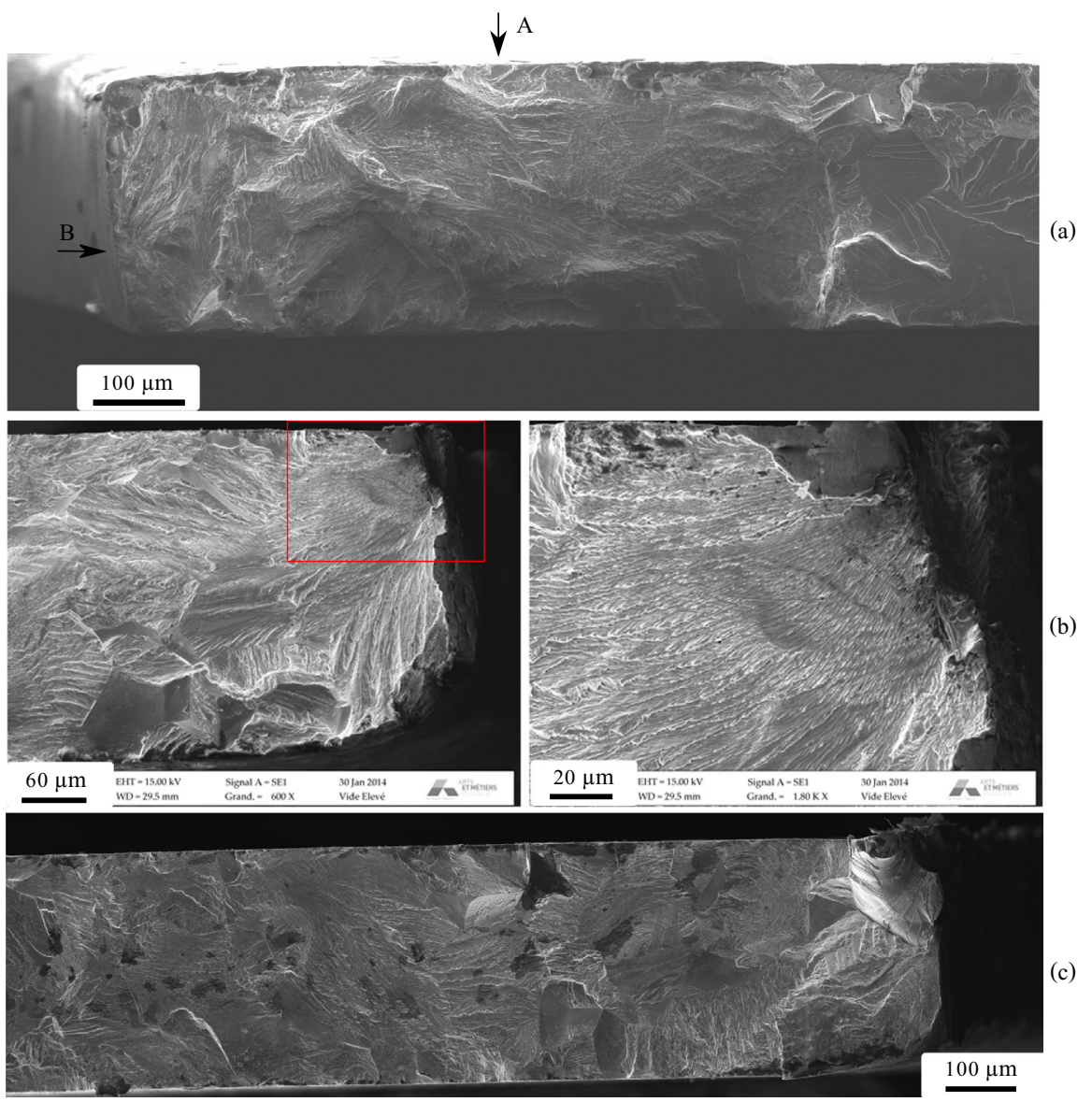

Fig. 9. (a) Fracture surface of polished edge specimen, (b) crack initiation defect (punched specimen), and (c) visible grain in the initiation zone (punched specimen). 


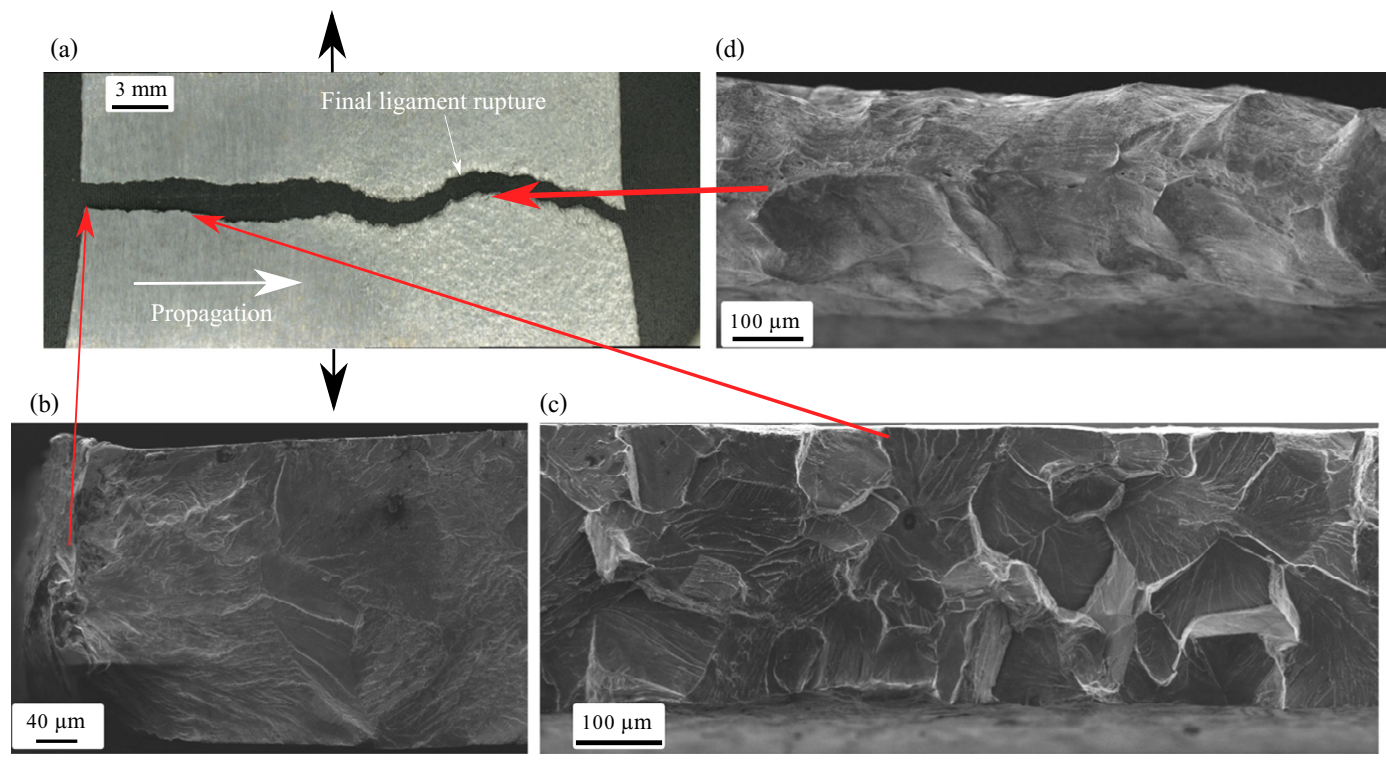

Fig. 10. Characteristic zones of fracture surfaces (punched specimen).

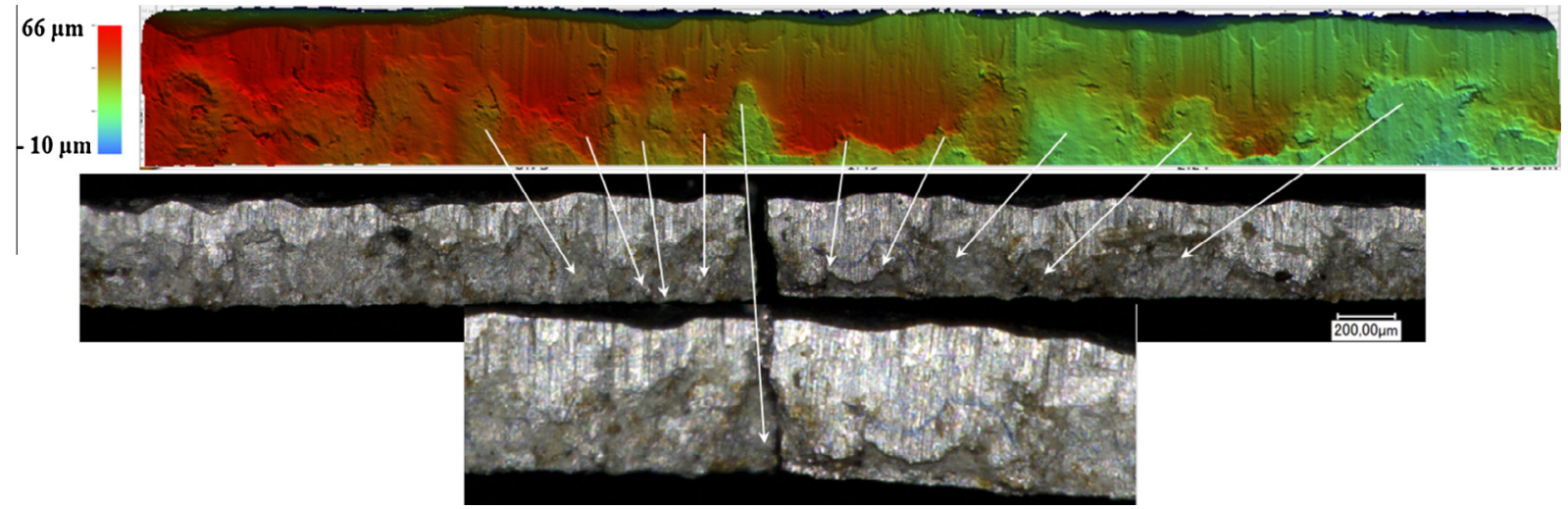

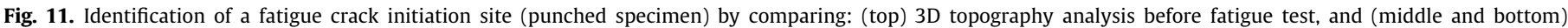
microscopic observation of the fracture surface.

on the face of the sheet with a $200 \mu \mathrm{m}$ spacing and on cross sections of the sheet with a $500 \mu \mathrm{m}$ or $200 \mu \mathrm{m}$ spacing give similar mean values: $211 \mathrm{HV}, 206 \mathrm{HV}$ and $204 \mathrm{HV}$, respectively.

In order to determine the depth of the region which is hardened because of the plastic strains resulting from punching operations, micro-hardness measurements were performed at different distances from a punched edge (Fig. 12d). Indentations are spaced with a $75 \mu \mathrm{m}$ distance, using a $100 \mathrm{~g}$ mass. When approaching the punched edge, a significant micro-hardness increase is observed. Indeed, while the mean value is about $210 \mathrm{HV}$ (without considering the first $200 \mu \mathrm{m}$ exhibiting the hardness peak), a value of $285 \mathrm{HV}$ is obtained for a depth of $50 \mu \mathrm{m}$. According to the in-depth evolution of micro-hardness, the region affected by punching operations is $200 \mu \mathrm{m}$ deep. Additional micro-hardness measurements were performed at different distances from a polished edge (Fig. 12d). The zone which is removed as a result of polishing is about $200 \mu \mathrm{m}$ deep, as a result no increase is observed when approaching the edge. The mean value is $208 \mathrm{HV}$, close to that obtained for the punched edge.

\subsection{Residual stress analyses}

The evolution of longitudinal residual stresses $\sigma_{y y}$ as a function of depth for a stack of 10 punched specimens is presented in Fig. 13a. Important surface tensile residual stresses (about $330 \mathrm{MPa}$ ) exist and maximum values (about $430 \mathrm{MPa}$ ) are observed for a depth of $50 \mu \mathrm{m}$. From 50 to $180 \mu \mathrm{m}$, residual stresses are found to decrease progressively. It is worth noticing that the depth up to which significant residual stresses exist is comparable to the depth which has been plastically deformed during punching operations. The development of residual stresses during punching operations thus seems to be governed by the plastic deformation gradient. When the depth is superior to $180 \mu \mathrm{m}$, because very few grains diffract together, uncertainties become important and residual stress values cannot be estimated with enough confidence.

The evolution of residual stresses along the longitudinal direction is plotted in Fig. 13a for polished edge specimens. In contrast with punched specimens, polished specimens exhibit significant compressive surface residual stresses $(-250 \mathrm{MPa})$. While the 


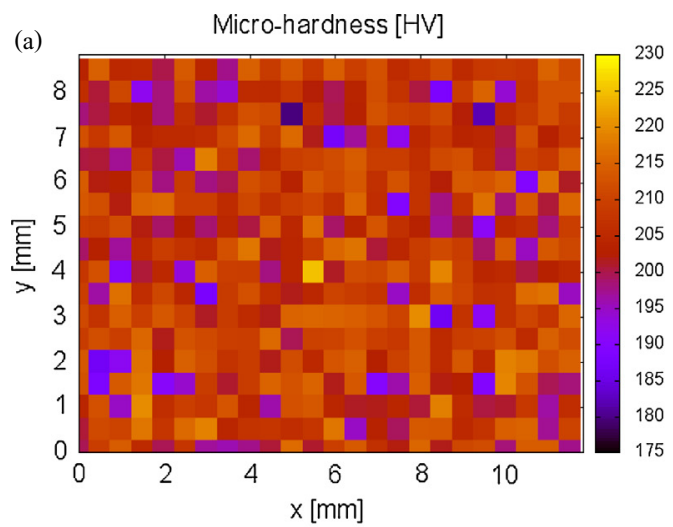

(b)

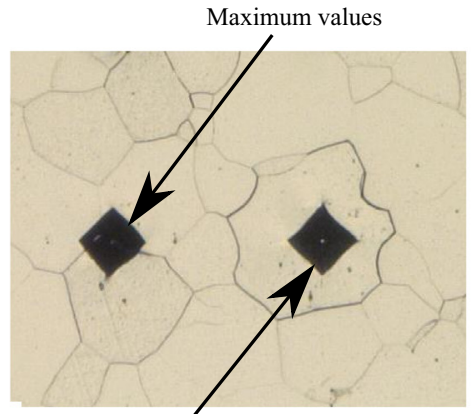

Minimum values
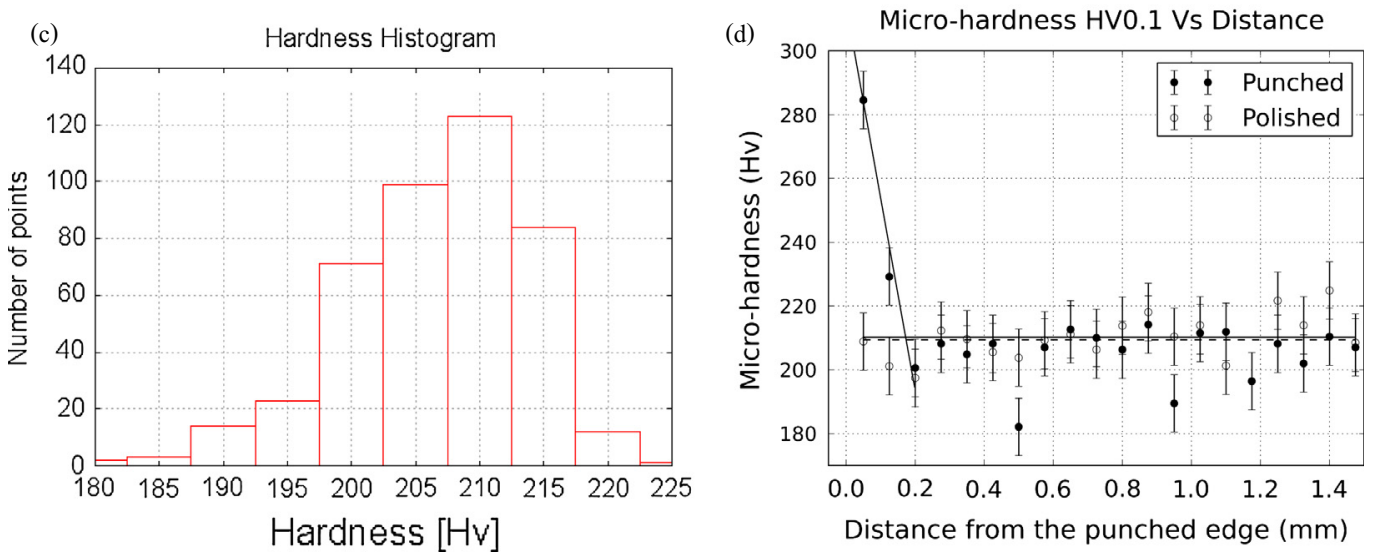

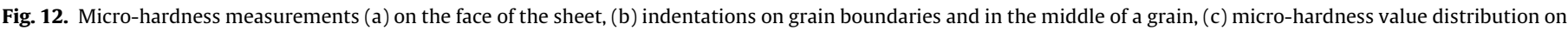
the face, and (d) micro-hardness measurements at different distances from a punched or polished edge.

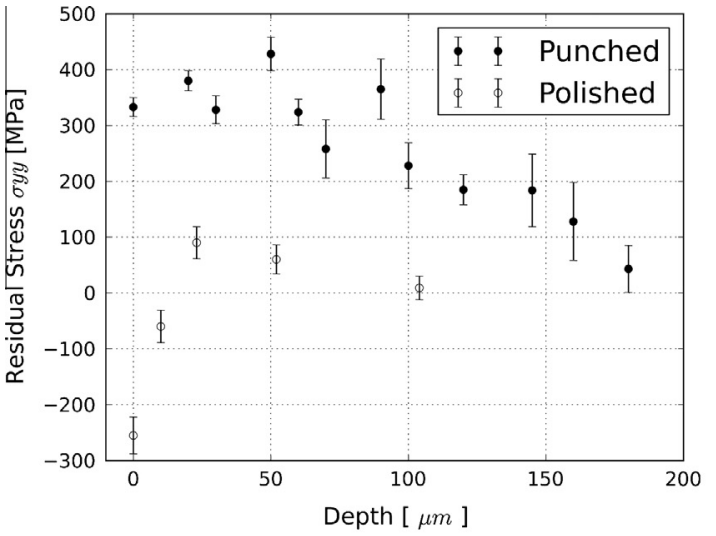

(a)

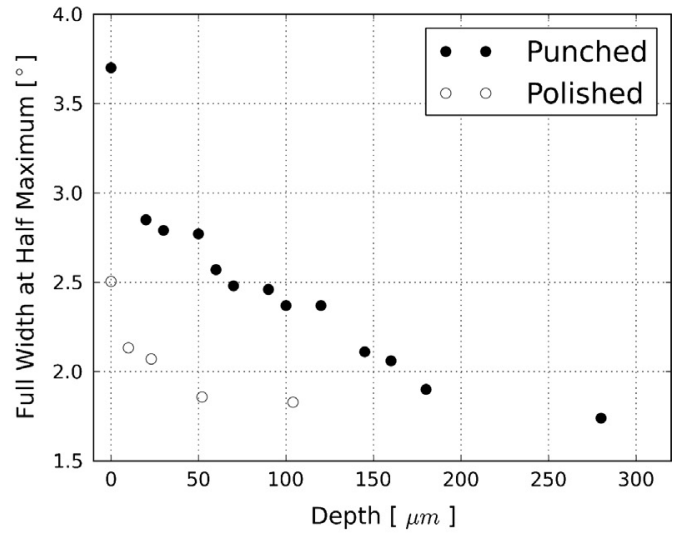

(b)

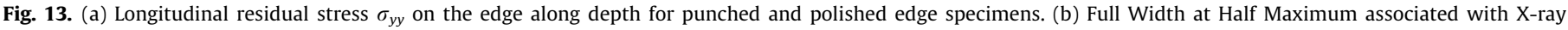
analysis.

compressive region is about $10 \mu \mathrm{m}$ deep, tensile residual stresses, with a maximum value of $90 \mathrm{MPa}$, are observed between 10 and $100 \mu \mathrm{m}$. Because both the surface values and in-depth distributions are very different, residual stresses are probably an important element for understanding the differences between polished specimens and punched specimens. The difference between punched and polished specimens is related to the development of plastic strain incompatibilities during fabrication operations (i.e. punching only or punching and polishing). For punching operations, surface tensile residual stresses are generated as a result of the important deformation gradients imposed by the shearing process [8]. For polishing operations, the introduction of superficial plastic strains is usually responsible for the development of surface compressive residual stresses [19]. However, since polished specimens were first punched and then polished, one may wonder whether the final residual stress state is influenced by previous punching operations or not. In the present case, because polishing operations allow for a complete removal of the $200 \mu \mathrm{m}$ deep hardened zone, the surface compressive residual stresses are expected to be solely due to polishing operations.

An important characteristic of diffraction peaks is the Full Width at Half Maximum (FWHM) which is connected to the 
Table 3

Residual stress relaxation after fatigue tests.

\begin{tabular}{llll}
\hline Residual stress & & $\sigma_{y y}(\mathrm{MPa})$ & FWHM $\left(^{\circ}\right)$ \\
\hline Before fatigue test & & 338 & 3.69 \\
After fatigue test & $R=0.1$ & 317 & 3.59 \\
& $R=0.5$ & 445 & 3.44 \\
\hline
\end{tabular}

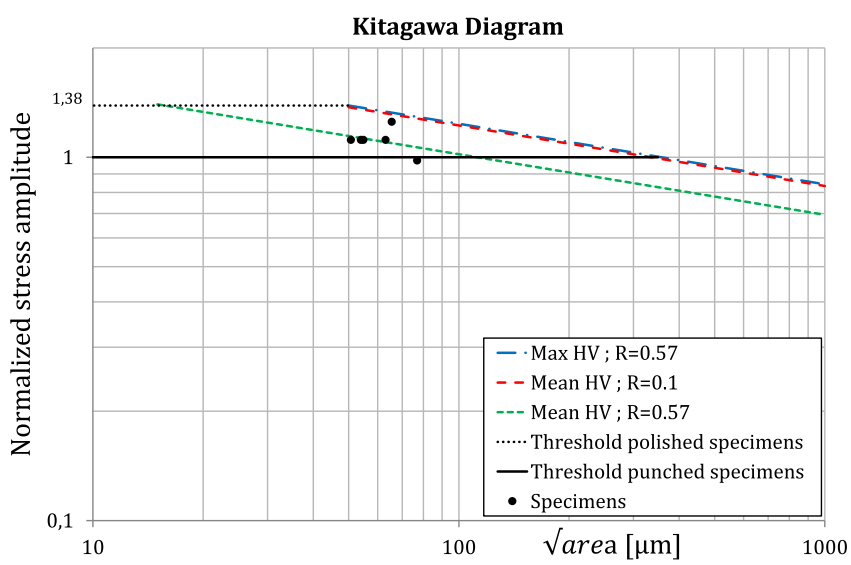

Fig. 14. Kitagawa diagram of punched and polished specimens.

concentration of crystalline defects. Since hardening is explained by the multiplication of dislocations, the evolution of the FWHM allows for a qualitative evaluation of hardening. The evolution of the FWHM as a function of depth is plotted for punched and polished specimens in Fig. 13b. For punched specimens, FWHM values are found to decrease up to a depth of $200 \mu \mathrm{m}$. The FWHM results are thus consistent with the results obtained from micro-hardness measurements (Fig. 12d). Also, while the minimum depth for micro-hardness measurements is $50 \mu \mathrm{m}, \mathrm{X}$-ray diffraction techniques offer higher spatial resolutions. More specifically, because a significant decrease of the FWHM is observed from $0 \mu \mathrm{m}$ to $50 \mu \mathrm{m}$, the superficial hardness is probably very superior to $285 \mathrm{HV}$ on punched edges.

In comparison with punching, the depth which is affected by polishing operations is much lower (Fig. 13b). Indeed, for polished specimens, the FWHM is observed to decrease rapidly and the asymptotic value is reached for a depth of $50 \mu \mathrm{m}$. Therefore, the influence of local hardening is largely reduced but not completely suppressed with polishing operations.

In order to detect some possible redistributions of the residual stress field during fatigue tests, some additional analyses were performed on punched specimens after fatigue tests (experiencing no crack initiation after $5 \times 10^{6}$ cycles). The experimental set up described earlier has been used to estimate the surface residual stresses along the longitudinal direction $\left(\sigma_{y y}\right)$ for two different loading conditions. More specifically, residual stresses were estimated for some unbroken specimens that have been tested until $5 \times 10^{6}$ cycles with a loading ratio of either $R=0.1$ or $R=0.5$. For each loading ratio, the stress amplitude is approximately equal to the median fatigue strength at $5 \times 10^{6}$ cycles. The results, which correspond to average values obtained for three different points on the edge, are presented in Table 3. In comparison with the initial residual stress state, no significant redistribution is observed for the loading ratio $R=0.1$ but an important increase (about $110 \mathrm{MPa}$ ) is obtained for $R=0.5$. Indeed, while maximum applied stresses remain inferior to the yield strength for $R=0.1$, they exceed the yield strength for $R=0.5$. The plastic strains resulting from these loading conditions thus allow for a redistribution of the residual stress field. Since no important increase of the surface FWHM has been observed for tested specimens, the redistribution of residual stresses is likely caused by a plastic activity occurring at a significant distance from punched edges. Indeed, though the superposition of the residual and applied stress fields should promote plasticity near punched edges, cyclic plasticity does not occur in this region because punching-induced local hardening is important. Nevertheless, at a sufficient distance from punched edges, the influence of local hardening reduces and the yield strength is exceeded during fatigue tests if maximum applied stresses are high enough. The residual stress redistribution process is thus governed by a competition between the influence of applied stresses, residual stresses and local hardening. As a result of this competition, plastic strain incompatibilities are reinforced and higher surface tensile residual stresses are needed to maintain static equilibrium for $R=0.5$.

\section{High cycle fatigue strength assessment}

Based on the optical profilometry scans of punched edges, the intersection surface between typical critical defects (fatigue crack initiation sites, see Fig. 11) and the $(X, Z)$ plane (perpendicular to the traction axis, see Fig. 3 ) was measured. The square root of this surface, defined by Murakami [13] as the flaw size, is about $60 \mu \mathrm{m}$. According to the Murakami approximation, the empirical relation between the fatigue strength in terms of both the stress amplitude and the flaw size of typical defects is:

$\sigma_{D}=\frac{A(\mathrm{HV}+120)}{\sqrt{\text { area }}^{1 / 6}} \times\left(\frac{1-R}{2}\right)^{\alpha}$

with $\sigma_{D}$ : median fatigue strength at $5 \times 10^{6}$ cycles, $A=1.43$ for surface flaws, HV: material hardness, $\sqrt{\text { area: }}$ square root of the projected area of a flaw on the plane experiencing the maximum normal stress and $R$ : loading ratio. $\alpha$ is the mean stress sensitivity factor whose definition is:

$\alpha=0.226+\mathrm{HV} \times 10^{-4}$

The Kitagawa diagram obtained using the Murakami criterion is presented in Fig. 14. Three different assumptions have been used for plotting this diagram:

- The first threshold line (red line) is obtained with the hardness mean value $(210 \mathrm{HV})$ and does not account for the influence of residual stresses.

- The second threshold line (green line) also considers the hardness mean value $(210 \mathrm{HV})$ but includes the influence of residual stresses. Residual stresses are treated as a static stress which is superimposed to the applied cyclic stress. The static stress is calculated by considering the average residual stress over a depth ranging from $0 \mu \mathrm{m}$ to $60 \mu \mathrm{m}$, the typical critical flaw size measured by optical profilometry. A stress ratio of 0.57 is thus used to account for the influence of residual stresses.

- The third threshold line (blue line) is obtained by considering the influence of both local hardening and residual stresses. The influence of local hardening is represented through the surface hardness value (285 HV).

Depending on the assumptions, the minimum flaw size affecting the fatigue strength is about $45 \mu \mathrm{m}(210 \mathrm{HV}$ and $R=0.1)$, $15 \mu \mathrm{m}(210 \mathrm{HV}$ and $R=0.57)$ and $50 \mu \mathrm{m}(285 \mathrm{HV}$ and $R=0.57)$ according to the Murakami criterion. The application of the Murakami criterion is therefore strongly dependent on the chosen assumptions and a particular attention must be paid to the choice of either surface or bulk quantities for calculating the criterion. In the present case, since the $30 \%$ fatigue strength drop is observed 
for punched specimens with critical flaw sizes ranging from $50 \mu \mathrm{m}$ to $80 \mu \mathrm{m}$, the best agreement is obtained when the effect of residual stresses is accounted for, but when the influence of local hardening is not considered (green ${ }^{1}$ line in Fig. 14).

\section{Conclusions}

In this paper, the impact of punching on the high cycle fatigue strength of thin steel sheets was investigated. The material of interest is a Fe-Si alloy, for which the grain size is comparable to the sheet thickness. According to the fatigue test results obtained on punched specimens, the mean normal stress sensitivity of the thin sheet is in agreement with the Goodman line in the high cycle fatigue regime $\left(5 \times 10^{6}\right.$ cycles). Also, when compared to polished edge specimens, a significant decrease of the fatigue strength is observed for punched specimens. Different factors are responsible for the degradation of the fatigue resistance. First, geometrical defects resulting from punching operations are found to promote crack initiation. Three dimensional surface topography analyses were performed to determine the geometrical features of the defects being responsible for fatigue crack initiation. According to the results, initiation often occurs on a defect located in the fracture zone of the edge. Second, important tensile residual stresses were observed on punched edges. Such tensile stresses were found to exist up to a depth of about $180 \mu \mathrm{m}$. Depending on the loading conditions, some redistributions of the residual stress field are observed during fatigue tests. Indeed, surface residual stresses along the longitudinal direction may increase during fatigue tests under $R=0.5$ because of the local hardening of the edge due to punching and plasticity in the specimen center. Finally, according to both micro-hardness measurements and diffraction data, punching operations generate a significant hardening up to a depth of $200 \mu \mathrm{m}$.

Based on the experimental results, the relevance of the Murakami criterion has been evaluated. The agreement with the experimental data is found to be strongly dependent on the choice of either surface or bulk quantities for calculating the criterion. In the present case, the experimental results are correctly reproduced when the influence of residual stresses is considered but when the impact of local hardening is not accounted for. This approach however remains phenomenological and further studies will have to be carried out to better explain these results.

Future work will include the development of a finite element model to better quantify the role of defects. The stress and strain fields obtained from such simulations will allow for introducing a non-local HCF criterion [13-18] accounting for the influence of defects when designing electric motor parts. Since the degradation of fatigue properties is explained by both tensile residual stresses and geometrical defects, some fatigue tests will be run on some additional configurations to try to separate the respective contributions of mechanical and geometrical alterations. Finally, since the defect size is comparable to the mean grain size, a polycrystalline finite element model will be developed to better understand the interactions between microstructural heterogeneities and fatigue damage.

\section{References}

[1] Lara A, Picas I, Casellas D. Effect of the cutting process on the fatigue behaviour of press hardened and high strength dual phase steels. J Mater Process Technol 2013;213:1908-19.

[2] Sanchez L, Gutierrez-Solana F, Pesquera D. Fatigue behaviour of punched structural plates. Eng Fail Anal 2004:751-64.

[3] Kunihiro S, Masayoshi I, Youichi N, Masaaki Y. Influence of shearing process on domain structure and magnetic properties of non-oriented electrical steel. J Magn Magn Mater 2006:e513-5.

[4] Maurel V, Ossart F, Billardon R. Residual stresses in punched laminations: phenomenological analysis. J Appl Phys 2003;93:7106.

[5] Pulnikov A, Baudouin P, Melkebeek J. Induced stresses due to the mechanical cutting of non-oriented electrical steels. J Magn Magn Mater 2003:355-7.

[6] Böhling M, Bauch J, Ullrich H-J. Effect of the cutting technique on the residual stress distribution of cut edges in $\mathrm{FeSi}_{3}$ transformer sheets. Cryst Res Technol 2009:1185-91.

[7] Loisos G, Moses AJ. Effect of mechanical and Nd:YAG laser cutting on magnetic flux distribution near the cut edge of non-oriented steels. J Mater Process Technol 2005:161:151-5.

[8] Achouri M, Gildemyn E, Germain G, Dal Santo P, Potiron A. Influence of the edge rounding process on the behaviour of blanked parts: numerical predictions with experimental correlation. Int J Adv Manuf Technol 2014;71 (5-8):1019-32.

[9] Hubert O. Influence des contraintes internes et de la structure des dislocations sur les couplages magnétomécaniques dans les alliages $\mathrm{Fe}-3 \% \mathrm{Si}$ à grains non orientés. PhD thesis. Université de Technologie de Compiègne; 1998 [in French].

[10] Baudouin P, De Wulf M, Kestens L, Houbaert Y. The effect of the guillotine clearance on the magnetic properties of electrical steels. J Magn Magn Mater 2003:32-40.

[11] Lu J. Handbook of measurement of residual stresses. Fairmont Press; 1996.

[12] Noyan IC, Cohen JB. Residual stress - measurement by diffraction and interpretation. New York-Berlin-Heidelberg-London-Paris-Tokyo: SpringerVerlag; 1987.

[13] Murakami Y. Metal fatigue: effect of small defects and non-metallic inclusions. Elsevier; 2002.

[14] Banvillet A, Palin-Luc T, Lasserre S. A volumetric energy based high cycle multiaxial fatigue criterion. Int J Fatigue 2003;25:755-69.

[15] Froustey C, Lasserre S. Multiaxial fatigue endurance of 30NCD16 steel. Int J Fatigue 1989:11(3):169-75.

[16] Gadouini H, Nadot Y, Rebours C. Influence of mean stress on the multiaxial fatigue behaviour of defective materials. Int J Fatigue 2008;30:1623-33.

[17] Palin-Luc T, Lasserre S. An energy based criterion for high cycle multiaxial fatigue. Eur J Mech A/Solids 1998;17(2):237-51.

[18] Nadot Y, Billaudeau T. Multiaxial fatigue limit criterion for defective materials. Eng Fract Mech 2006;73:112-33.

[19] Itoga H, Tokaji K, Nakajima M, Ko H-N. Effect of surface roughness on stepwise S-N characteristics in high strength steel. Int J Fatigue 2003;25:379-85. 